\title{
BMJ Open Psychological impact of COVID-19 outbreak among Jimma University Medical Centere visitors in Southwestern Ethiopia: a cross- sectional study
}

\author{
Yimenu Yitayih (D), Yohannes Kebede Lemu, Seblework Mekonen, \\ Mohammed Mecha, Argaw Ambelu
}

To cite: Yitayih Y, Lemu YK, Mekonen S, et al. Psychological impact of COVID-19 outbreak among Jimma University Medical Centere visitors in Southwestern Ethiopia: a crosssectional study. BMJ Open 2021;11:e043185. doi:10.1136/ bmjopen-2020-043185

- Prepublication history and additional materials for this paper is available online. To view these files, please visit the journal online (http://dx.doi. org/10.1136/bmjopen-2020043185).

Received 27 July 2020

Revised 15 December 2020

Accepted 16 December 2020

Check for updates

(C) Author(s) (or their employer(s)) 2021. Re-use permitted under CC BY-NC. No commercial re-use. See rights and permissions. Published by BMJ.

Institute of Health, Jimma University, Jimma, Ethiopia

Correspondence to

Dr Argaw Ambelu;

aambelu@yahoo.com

\section{ABSTRACT}

Background COVID-19 has posed several medical, psychosocial and economic impacts among the majority of the society. The ambiguity of its transmission, the intense desire of self-protection, family, and friends, the unknown impact of catching the disease itself, unstoppable spread, the panic and outright misinformation lead to acute stress reaction syndrome. However, reliable data related to this contagion lack the prevalence of acute stress reaction syndrome and associated factors among Jimma University Medical Centre hospital visitors in Southwestern Ethiopia. Aims The main objective of the study was to assess the prevalence and factors associated with acute stress reaction syndrome during the COVID-19 outbreak among Jimma University Medical Centre Hospital visitors, Ethiopia. Methods An interviewer-administered cross-sectional study was conducted among 247 visitors of the Jimma University Medical Centre in Ethiopia. The study was conducted within 2 weeks of the first COVID-19 cases detected on 13 March 2020 in Ethiopia. Data on demographic and socioeconomic status were collected during the interview using structured questionnaires. The psychological impact was assessed using the Impact of Event Scale-Revised, and symptoms of insomnia were measured using the Insomnia Severity Index. Social support was evaluated using 0slo three-item Social Support Scale. Logistic regression was employed to determine the associations between dependent and independent variables. Besides, psychosocial stress score was generated using principal component analysis. A paired permutation test was also performed to determine the variability of psychosocial stress between groups. Results The mean age of participants was 30.47 years, and $76.5 \%$ of the participants were male. Acute stress reaction syndrome was detected in $44.1 \%$ of hospital visitors. Of the participants, $38.5 \%, 17.4 \%, 8.5 \%$ and $35.6 \%$ had a minimal, mild, moderate and severe psychological impact, respectively. Factors positively associated with acute stress reaction syndrome were individuals who perceived that COVID-19 leads to stigma (adjusted OR (AOR): $3.24,95 \% \mathrm{Cl} 1.11$ to 9.45), mild insomnia (AOR: $14.74,95 \% \mathrm{Cl} 6.14$ to 35.40 ), moderate to severe insomnia (AOR: $35.1,95 \% \mathrm{Cl} 10.76$ to 114.66 ),

\section{Strengths and limitations of this study}

- To the best of our knowledge, this study was the first of its kind in assessing the psychological impact of the COVID-19 outbreaks in Ethiopia.

- We collect the data after 2 weeks after the COVID-19 outbreak, and the period of exposure to the COVID-19 was short.

- We could only study the acute psychological impact and might not be generalised to subacute and longterm psychological complications if the outbreak continues.

- Another limitation is that respondents might have provided socially desirable responses.

- This cross-sectional study prohibits the causal analysis, and we do not determine between the association of insomnia and acute stress reaction syndrome of a population.

low social support (AOR: $4.08,95 \% \mathrm{Cl} 1.31$ to 12.67 ) and governmental employees (AOR: $8.09,95 \% \mathrm{Cl} 1.38$ to 47.18).

Conclusion The study revealed the existence of a high prevalence of acute stress reaction syndrome during the COVID-19 outbreak among different groups of the community. Therefore, our results will contribute to the global awareness of the psychological impact of the COVID-19 outbreak.

\section{INTRODUCTION}

The COVID-19 pandemic started in China is becoming a global health threat. ${ }^{1}$ The disease is registered as the largest outbreak of atypical pneumonia since the SARS outbreak in 2003. ${ }^{2}$ In January 2020, the WHO declared the current novel COVID-19 to be a Public Health Emergency of International Concern and in March 2020 as a pandemic disease. ${ }^{3}$

The outbreak of COVID-19 in Ethiopia was officially declared on 13 March 2020, after one Japanese arrived in Ethiopia 
following his Burkina Faso trip and tested positive for the SARS-CoV-2. The COVID-19 outbreak is believed to have unpredictable events that are marked by a sense of uncertainty, confusion and urgency. Furthermore, uncertainties related to the transmission of the disease, the intense desire to protect family and friends (and yourself), the unknown impact of catching the disease itself, the inexorable spread, the panic, and outright misinformation led the community to stress.

The Emergency Committee of WHO has stated that the COVID-19 spread might be interrupted by social distancing, early detection, quarantine, prompt treatment and the implementation of a robust contacts tracing system. ${ }^{4}$ Other measures include ascertaining clinical severity, the extent of transmission and optimising case treatment. In the absence of vaccines, the relevance of non-pharmaceutical interventions such as quarantine remains frontline measures in averting the spread of the COVID-19 pandemic. ${ }^{5}$ In Wuhan, China, these preventive measures were implemented alongside city lockdown, mass quarantine and school closure during the COVID-19 outbreak in January and February 2020. ${ }^{6}$

Health emergency measures like quarantine, social distancing to control the spread of the COVID-19 disease could have a considerable impact on the psychological health of the population. Separation from loved ones, the loss of freedom, uncertainty over disease status and boredom can, on occasion, create dramatic effects. Suicide has been reported, ${ }^{7}$ substantial anger generated and complaints brought following the imposition of quarantine in previous outbreaks. ${ }^{8}$ In the reviewed studies, the financial loss as a result of quarantine created serious socioeconomic distress ${ }^{9}$ and was found to be a risk factor for symptoms of psychological disorders, ${ }^{10}$ and both anger and anxiety remain several months after quarantine. ${ }^{11}$ The study revealed that quarantine of those suspected of contracting or carrying the virus could provoke substantial acute stress disorder, depression, post-traumatic stress disorder, insomnia, irritability and emotional exhaustion. ${ }^{12}$

Currently, the knowledge missed and what is not known is how the community views and responses to too many complex issues related to the COVID-19 outbreak. Previous experiences with large outbreaks of serious illnesses have indicated that the potential for panic and worries are often a lot greater than the risk for the disease. ${ }^{1314}$

A study in outbreak control rarely includes information about the population on psychological responses to the infection and its relevance to outbreak control. Sufficient information is not available regarding the mental health impact of COVID-19 related quarantine in Ethiopia. While many resources are devoted to biomedical research and medical treatment, psychosocial problems of COVID-19 among the community are mainly ignored. Therefore, to assist the medical and public health intervention planners against the COVID-19 epidemic, visitors of Jimma Medical Center (JMC) were surveyed to investigate the psychological impact of the community. Inaddition to the determination of the prevalence of acute stress reaction (ASR) syndrome, our hypotheses are: most medical centre visitors are affected by insominia, and poor social support is significantly associated with ASR syndrome.

\section{METHODS}

\section{Study design and setting}

We used a hospital-based cross-sectional study design to assess the psychosocial and associated factors posed by COVID-19 to identify focus areas of intervention. This study was conducted within 2 weeks of the first COVID-19 cases detected in Ethiopia from 22 to 28 March 2020, at JMC, which is the highest healthcare facility in Southwestern Ethiopia. JMC provides referral medical services sent from different health facilities in Southwest Ethiopia. JMC is leading most of the prevention, detection and patient care related to COVID-19 in the region. It is also strengthening its capacities and fulfilling facilities for quarantine and treatment services.

\section{Population and sample}

All visitors coming from different districts of Southwestern Ethiopia to JMC were the study participants. Both clients and patients visiting the hospital were the source population. The visitors' samples were those who can comfortably respond to the questions forwarded by the data collect.

\section{Sample size determination and sampling}

The single population proportion formula was used to determine the sample size. Accordingly, the formula for sample size determination used is: $\mathrm{n}=(\mathrm{Z} \alpha / 2) 2 *[(\mathrm{p} 1 \mathrm{q} 1) /$ (d)2], where $n$ is visitors sample size, $Z \alpha / 2$ is the reliability coefficient of SE at $5 \%$ level of significance, $p$ is the proportion of JMC visitors who have no ASR syndrome due to COVID-19 (50\%, no previous study found) and d refers to the level of SE tolerated (5\%) to accept the magnitude of ASR syndrome assumed. Hence, the sample size was calculated to be 247 visitors after adjusted for the total number of visitors expected to come to JMC for 1 week (rapid assessment). Then, an equal proportion of the sample stigmatisation to major wards/clinics in JMC. Finally, consecutive sampling was applied until the allocated sample size was filled (see figure 1).

\section{Measurements}

The questionnaire consisted: sociodemographic characteristics, the psychological response, insomnia and social support (see online supplemental material). Demographic variables included age, gender, marital status, education and occupation. Average monthly income was classified as $\$<15.18, \$ 15.18-45.53, \$ 45.56-75.91, \$ 75.94-$ 106.28 and $\$>106.31$.

The Impact of Events Scale Revised (IES-R), ${ }^{15}$ which is validated in the Ethiopian context during the study conducted in Tigray, ${ }^{16}$ is used to measure the psychological 
247 visitors at Jimma medical centre from 22〈March \} 2020 to $28 \backslash$ March $\backslash 2020$

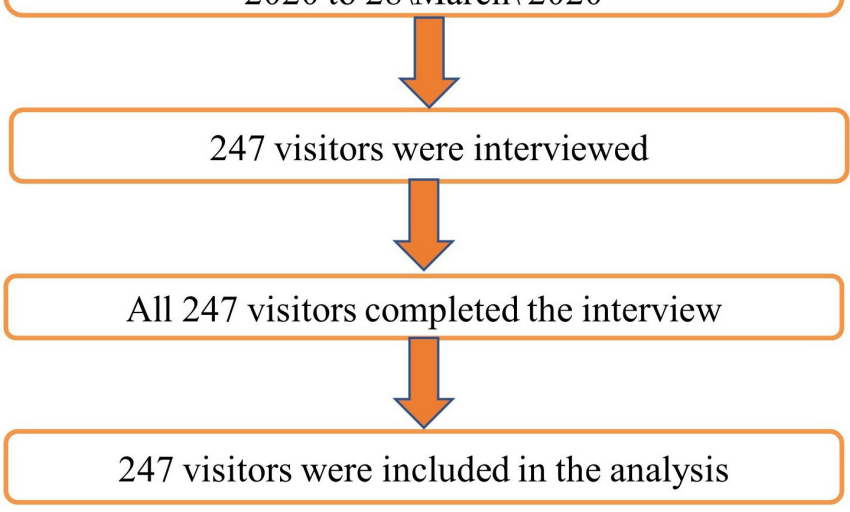

Figure 1 Identification of survey participants.

response to traumatic stressors in this study to assess post-traumatic stress symptoms experienced by subjects during the last 1 week following the COVID-19 outbreak. Respondents were informed that the items constitute a list of ways they may have felt or behaved in the previous week, and they indicate the frequency of occurrence of each symptom on a four-point scale. The IES-R has 22 items with a Likert rating scale ranging from 0 (not at all) to 4 (extremely). The full assessment scale contains 22 items (scored from 0 to 88 ) with confirmed reliability and validity that measures post-traumatic stress disorder (PTSD) symptoms across diverse cultural settings. The IES-R is generally not used to diagnose PTSD in clinical settings, but it is widely used for screening at-risk patients with PTSD. ${ }^{2}$ The total IES-R scores were divided into 0-23 normal (no impact), 24-32 (mild psychological impact), 33-36 (moderate psychological impact) and $>37$ (severe psychological impact). ${ }^{17}$ The total IES-R score equal to or greater than 33 signifies the likely presence of ASR syndrome, ${ }^{18} 19$ and the reliability in this study was 0.90 (Cronbach's $\alpha$ ).

Symptoms of insomnia were measured by the Insomnia Severity Index (ISI).$^{20}$ ISI was a scale that has been widely used to assess the nature, severity and impact of insomnia. It consisted of seven relevant items, and the final score was calculated in accordance with the 0-4 Likert scale. Answers to all questions ranged from 0 to 4 score and summed to give a total score that ranges from 0 to 28 , and the final score was divided into three classes: (1) 0-7: no insomnia; (2) 8-14: mild insomnia; and (3) 15-28: moderate to severe insomnia. The higher score a participant attained, the more severe insomnia suffered. The Cronbach's $\alpha$ was 0.843 indicating the acceptable internal consistency of the scale. $^{21}$

The Oslo three-item Social Support Scale, a threeitem question that assesses social support, was used to assess social support. It is scored in a range from 3 to 14, with three categories interpretation of the values: poor, moderate and strong. The reliability and validity score in Nigeria yielding Cronbach's $\alpha$ coefficient of 0.50 , and concurrent validity is low but significant. ${ }^{22}$ While stigma was assessed based on the endorsement of the statement if respondents think whether COVID-19 is causing stigma against people.

\section{Operational definition}

Acute stress reaction

Subjective distress caused by traumatic events, and the term ASR is related to Diagnostic and Statistical Manual of Mental Disorders, 4th Edition (DSM-IV) diagnosis of acute stress disorder. ${ }^{18}$

\section{Statistical analysis}

Statistical Package for Social Sciences (SPSS) V.22 for Windows was used to analyse the data. Statistical significance was defined at a $\mathrm{p}$ value of less than 0.05 . The reliability and internal consistency were assessed by calculating Cronbach's $\alpha$.

Frequency distribution was used to enumerate qualitative variables, while quantitative variables were described using the mean and SD. Multivariable logistic regression was employed to determine the associations between ASR syndrome against the variables related to sociodemographic factors, insomnia and the presence of social support. Besides, a psychosocial distress score was generated using principal component analyses of the 22 items of IES-R. The first principal component scores having a $35.9 \%$ variance that showed a representation of all the items were used to represent the psychosocial distress among different groups. Using the first component score, the distribution of the psychosocial distress was determined among the different grouping variables using box and whisker plots. A paired permutation test was performed using the $\mathrm{R}$ statistical package ${ }^{23}$ if the psychosocial distress score could vary between groups of study participants.

\section{Patient and public involvement}

During the design and preparation of the data collection tool, no study participants have involved in the development of the research question and outcome measures. This assessment was conducted in collaboration with organisations working with Jimma University and an active member of Jimma University in those organisations. The finding will be communicated through publication in peer-reviewed journals and be presented at the national level for stakeholders working with Jimma University.

\section{RESULT}

We enrolled 247 visitors to JMC in our study. The mean (SD) age of participants was 30.47 (10.20) years. Among all respondents, $189(76.5 \%)$ were male, $156(63.2 \%)$ of them had ever married and 148 (59.9\%) were Muslim by religion. Participants without formal education were 72 $(29.1 \%)$, and $21.0 \%$ of them were not able to read and write. One-third of the respondents, 77 (31.2\%) were farmers by occupation. More than half of the participants 
Table 1 Sociodemographic characteristics of visitors in Jimma Medical Center, Southwestern Ethiopia, $2020(n=247)$

\section{Participants ( $\mathrm{N}=247), \mathrm{n}(\%)$}

\begin{tabular}{lc}
\hline Sex & \\
Male & $189(76.5)$ \\
Female & $58(23.5)$ \\
Age (years) & \\
Mean & 30.47 \\
SD & 10.2 \\
Age groups (years) & \\
18-24 & $86(34.8)$ \\
$25-34$ & $85(34.4)$ \\
$35-44$ & $51(20.7)$ \\
$45-54$ & $18(7.3)$ \\
55-66 & $7(2.8)$ \\
Religion & \\
Muslim & $148(59.9)$ \\
Orthodox & $56(22.7)$ \\
Protestant & $39(15.8)$ \\
Others & $4(1.6)$ \\
\hline
\end{tabular}

Marital status

$\begin{array}{lr}\text { Single } & 91(36.8) \\ \text { Ever married } & 156(63.2)\end{array}$

Educational status

No formal education $72(29.1)$

Primary education $\quad 52(21.1)$

Secondary education $62(25.1)$

Higher education 61 (24.7)

Occupation

\begin{tabular}{lc} 
Farmer & $77(31.2)$ \\
Student & $75(30.4)$ \\
Centre & $38(15.4)$ \\
Private employed & $23(9.3)$ \\
Government employed & $34(13.8)$ \\
Income (in dollar) & \\
$<15.18$ & $126(51.0)$ \\
$15.18-45.53$ & $33(13.4)$ \\
$45.56-75.91$ & $34(13.8)$ \\
$75.94-106.28$ & $18(7.3)$ \\
$>106.31$ & $36(14.6)$ \\
\hline
\end{tabular}

*Other religion is for Catholic or Waqua Feta religion; $\mathrm{n}$

$(\%)=$ number of people and proportion.

(51\%) responded to have an annual income of less than 500 birrs (US\$14.8) per anum (table 1).

The psychological impact of the COVID-19 outbreak

Overall, $109(44.1 \%)$ participants scored 33 or more on the IES-R scale, suggesting that they had ASR syndrome due to the outbreak of COVID-19. The IES-R scores ranged from 0 to 88 , with a mean of 28.47. Of participants, $95(38.5 \%)$ reported minimal psychological impact (score $<23), 43(17.4 \%)$ rated mild psychological impact (scores 24-32), 21 (8.5\%) reported moderate psychological impact (scores 33-36) and $88(35.6 \%)$ severe psychological impact (score $>37$ ). The mean IES-R intrusion score (mean=12.9, $\mathrm{SD}=7.3$ ) was the highest, followed by the mean avoidance score (mean $=9.4, \mathrm{SD}=6.5$ ), and the hyperarousal scores (mean $=6.1, \mathrm{SD}=4.9$ ) was the lowest. Regarding the prevalence of ASR syndrome, the higher prevalence was observed in individuals with no formal education, having low income, male sex, being married and those who are farmers by occupation.

\section{Insomnia and social support}

Overall, $85(34.4 \%)$ had mild insomnia, and $40(16.2 \%)$ had moderate to severe insomnia during the outbreak of COVID-19. Scores suggestive of mild insomnia (ISI 8-14) were noted (in $52.3 \%$ of individuals with ASR syndrome) compared with $20.3 \%$ with no ASR syndrome.

Among the participants with ASR syndrome, $56.9 \%$ had poor social support, $35.8 \%$ had moderate and $7.3 \%$ had strong social support.

The component score of psychosocial distress among study groups with different insomnia status, young $(\leq 30$ years) and older age groups ( $>30$ years), marital status, literacy status and religious groups showed significant difference $(p$ value $=0.001$ ). Individuals with increasing insomnia had a linear increase in psychosocial distress. Participants over 30 years of age, males and married individuals showed higher psychosocial distress than the younger age group. The box and whisker plot (figure 2) indicates psychosocial stress variability among the different study participants.

\section{Factors associated with ASR syndrome}

Following the bivariate analysis, 11 factors were identified to be used for the subsequent multivariable logistic regression with ASR syndrome (table 2). Multivariable logistic regression analysis indicated that acute psychosocial stress reaction syndrome was positively associated with COVID-19 leads to stigma (AOR: 3.24, 95\% CI 1.11 to 9.45 ), mild insomnia (AOR: 14.74, 95\% CI 6.14 to 35.40), moderate to severe insomnia (AOR: $35.1,95 \%$ CI 10.76 to 114.66 ), poor social support (AOR: $4.08,95 \% \mathrm{CI}$ 1.31 to 12.67 ) and governmental employees (AOR: 8.09, 95\% CI 1.38 to 47.18 ) (table 2 ).

\section{DISCUSSION}

\section{Main findings}

To the best of our knowledge, this study was the first of its kind assessing the psychological impact of the COVID-19 outbreak in Ethiopia. Our research indicates that during the initial stages of the COVID-19 outbreak, $17.4 \%, 8.5 \%$ and $35.6 \%$ reported mild psychological impact, moderate psychological impact and severe psychological impact, 

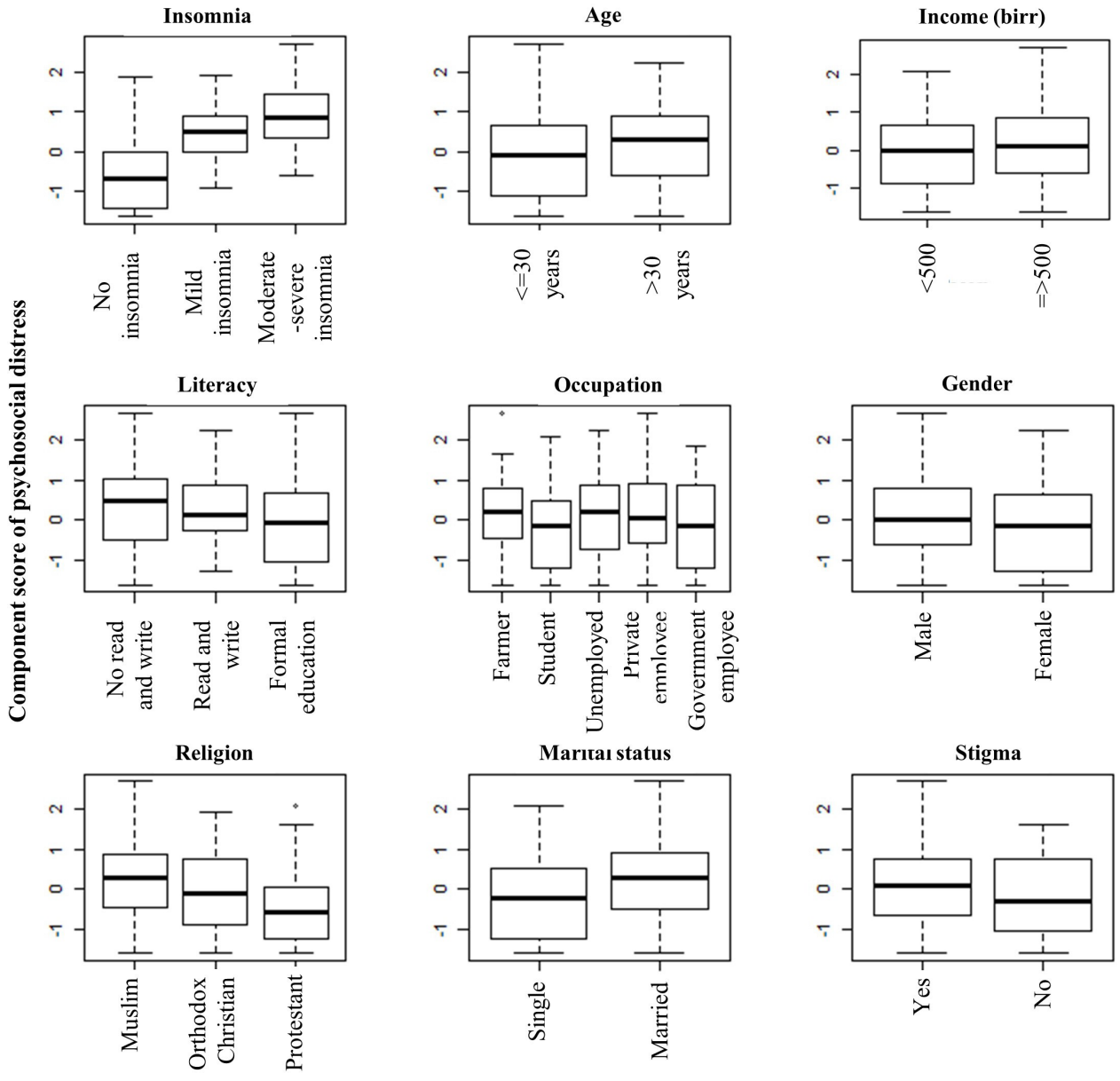

Figure 2 Level of psychosocial distress using box and whisker plot among the different groups of participants.

respectively. Of respondents, $44.1 \%$ of participants develop ASR syndrome, with $95 \%$ CI (38.5 to 50.2). Intrusive symptoms, such as recurrent feelings, mental images and feelings about COVID-19, were more common than hyperarousal and avoidance symptoms in the study population. These results are consistent with the findings from research regarding the COVID-19 outbreak in China, demonstrating that $53.8 \%$ of the general population experienced moderate or severe psychological impact during the outbreak. ${ }^{2425}$

Our study identified different factors that are associated with ASR syndrome. In particular, those who perceive COVID-19 leads to stigma, mild insomnia, moderate to severe insomnia, poor social support and government employees who had higher odds of developing ASR syndrome.

Individuals who perceive COVID-19 leads to stigma were three times more likely to develop ASR syndrome than their counterparts. The stigma is due to the fear of social isolation, lack of institutional service and verbal abuse that might lead to increased levels of psychological distress. Such a psychological level will also lead to delayed access to medical care, low adherence to medical therapy and reduced quality of life that has also been reported among HIV/AIDS and mental health patients. ${ }^{26}{ }^{27}$ Prior research has revealed that stigma-induced psychological distress and anxiety are associated with adverse mental health outcomes among patients with HIV/AIDS. ${ }^{28}$ Since HIV/AIDS and COVID-19 share similar stigmatising attributes, ${ }^{29}$ it is possible that COVID-19 related stigma may be contributing to the mental health complications among COVID-19 survivors. Drawing from lessons learnt from HIV/AIDS-related stigma, the COVID-19 survivor-centred and community-driven approach has been suggested that could contribute to COVID-19 survivors' recovery and community reintegration.

These include community long-term psychosocial counselling for COVID-19 survivors to enhance their coping skills, community education, recruitment and training of trusted opinion leaders that can spread accurate destigmatising messages within communities for COVID-19 affected communities. ${ }^{30}$ Older age groups (>30 years) and individuals with family responsibilities (married) in the meantime are highly stressed with the COVID-19 pandemic that needs targeted intervention.

The adjusted OR for ASR syndrome was higher among individuals with poor social support than individuals with strong support. Low levels of social support are often associated with increased morbidity and mortality in a host of medical illnesses. ${ }^{31}$ Indeed, a lack of social support can itself be a source of stress, leading to a long-term feeling of loneliness. ${ }^{32}$ Also, another study showed that the lack of social support strengthened the veterans 'perception of rejection' and led to feelings of detachment. ${ }^{32}$ As an external resource 
Table 2 Bivariable and multivariable independent associated factors of acute stress reaction syndrome among visitors of Jimma Medical Center, Southwestern Ethiopia, 2020 (N=247)

\section{Had acute stress No acute}

reaction syndrome, stress reaction

n (\%)

syndrome, $\mathbf{n}(\%)$

COR $(95 \% \mathrm{Cl})$

\section{Adjusted OR $(95 \% \mathrm{Cl}) \quad \mathrm{P}$ value}

Sex

$\begin{array}{lccccc}\text { Male } & 85(78.0) & 104(75.4) & 1.16(0.64 \text { to } 2.10) & 0.59(0.25 \text { to } 1.429) & 0.248 \\ \text { Female } & 24(22.0) & 34(24.6) & 1 & 1\end{array}$

Age group (years)

$\begin{array}{cccccc}18-24 & 32(29.4) & 54(39.1) & 3.56(0.41 \text { to } 30.88) & 8.91(0.356 \text { to } 222.89) & 0.183 \\ 25-34 & 40(36.7) & 45(32.6) & 5.33(0.62 \text { to } 46.22) & 11.89(0.54 \text { to } 260.82) & 0.116 \\ 35-44 & 25(22.9) & 26(18.8) & 5.77(0.65 \text { to } 51.40) & 4.56(0.21 \text { to } 98.82) & 0.333 \\ 45-54 & 11(10.1) & 7(5.1) & 9.43(0.93 \text { to } 95.89) & 8.14(0.31 \text { to } 214.32) & 0.209 \\ 55-66 & 1(0.9) & 6(4.3) & 1 & 1\end{array}$

Marital status

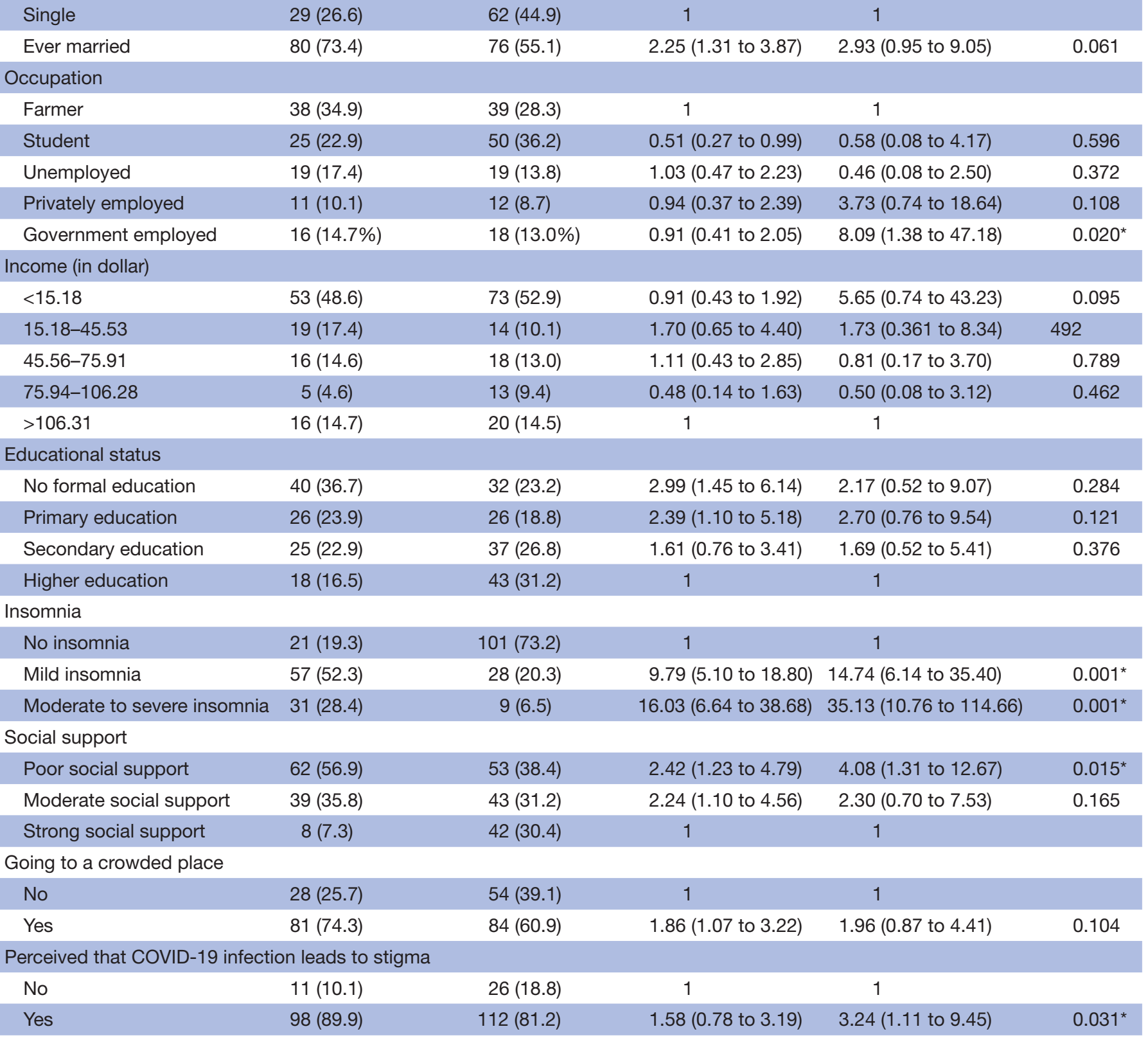

Practice hand washing to prevent COVID-19 infection 


\begin{tabular}{|c|c|c|c|c|c|}
\hline & $\begin{array}{l}\text { Had acute stress } \\
\text { reaction syndrome, } \\
\mathrm{n}(\%)\end{array}$ & $\begin{array}{l}\text { No acute } \\
\text { stress reaction } \\
\text { syndrome, } \mathrm{n}(\%)\end{array}$ & COR $(95 \% \mathrm{Cl})$ & Adjusted OR $(95 \% \mathrm{Cl})$ & $P$ value \\
\hline No & $30(27.5)$ & $26(18.8)$ & 1.64 (0.90 to 2.98$)$ & 1.28 (0.54 to 3.05$)$ & 0.568 \\
\hline Yes & $79(72.5)$ & $112(81.2)$ & 1 & 1 & \\
\hline
\end{tabular}

${ }^{*} \mathrm{P}<0.05$

aOR, adjusted OR; COR, Crud OR.

available to individuals under stress, social support functions as a buffer to improve the psychological condition. ${ }^{33}$

Mental illness can be moderated through social support, reduced genetic and environmental vulnerabilities, fostering effective coping strategies and the impact on multiple neurobiological factors. ${ }^{33}$ This finding will be necessary for policymakers and healthcare professionals to apply effective interventions specifically to increase social support for the community to tackle the COVID-19.

Of the factors for ASR syndrome, people with insomnia had higher odds of developing ASR syndrome than people with no insomnia because people with insomnia had hyperactivity of the Hypothalamic-Pituitary-Adre (HPA) axis. Such disorder may play a role in the development of ASRs in insomnias with an objective of short sleep duration. In contrast, psychological mechanisms, that is, inadequate coping resources and ruminative traits, may play such a role in insomnia. ${ }^{34}$ Another study found that that insomnia is highly comorbid with psychiatric disorders and is a risk factor for the development of psychological distress. ${ }^{35}$

Insomnia with objective short sleep duration was associated with a psychological profile consistent with depressed mood, fatigue, concerns about health and physical functioning, somatically focused anxiety and poor health status. ${ }^{36}$ Insomnia did not seem to be simply a symptom of past or current mental illness. However, it is a condition where individuals experience impairments in function life due to lack of sleep. The finding supports targeting the insomnia symptoms in selective preventive mental health initiatives, particularly during the outbreak of a disease.

\section{Implication of the study}

In any biological disaster, themes of anxiety, ambiguity and stigmatisation are common and may hinder appropriate medical and mental health interventions. Based on experience from past severe novel pneumonia outbreaks globally, preventing, detecting and intervening the mental health conditions should be an essential component of global health security efforts. The use of brief psychological response screeners is crucial and pressing goals for the health response to the COVID-19 outbreak. The outbreak response could increase the ability to identify and address the needs of the groups at risk and implementation of early psychological support interventions for affected people. Hence, early tackling of those factors could help to avert the substantial short-term and long-term effects of psychological impact on community health.

\section{Limitations}

Our study has limitations. We collected the data after 2weeks of the COVID-19 outbreak, limiting the generalisability of the findings. Therefore, the period of exposure to the COVID-19 was short, and we could only study the acute psychological impact and might not be generalised to subacute and long-term psychological complications if the outbreak continues. Furthermore, we did not test how many people were positive for COVID-19 infection. Another limitation is that respondents might have provided socially desirable responses. This study was a cross-sectional study not able to determine cause-and-effect relationships between insomnia and psychological distress. Finally, longitudinal studies might help to assess for development or even a potential rebound effect of psychological distress once the impending threat of COVID-19 is resolved.

\section{CONCLUSION AND RECOMMENDATIONS}

We found a high prevalence of ASR syndrome during the COVID-19 outbreak among visitors of JMC. It is confirmed that the participants who perceived that COVID-19 leads to stigma, mild insomnia, moderate to severe insomnia, poor social support, and government employees are associated with ASR syndrome. We strongly hope that our results will contribute to the global awareness of the psychological impact of the COVID-19 outbreak. Our findings deliver guidance to the health authorities to focus on decreasing COVID-19 related stigma and insomnia and strengthen the social support system to reduce ASR on this COVID-19 outbreak. Stress relief activities such as physical exercise, peer support, yoga, meditation or religious or spirituality-related practices might act as early and prompt prevention for psychological distress. ${ }^{37}$

Thus, it is likely that stigma reduction strategies will help reduce the mental health burden among the community. Our findings also directly inform the development of a new psychological crisis intervention that can minimise psychological impact, stigma, insomnia, stress during the outbreak of COVID-19 and other similar contagions.

Acknowledgements We are grateful to the Ethical Review Board of the Institute of Health, Jimma University, for granting ethical clearance. Our deep gratitude also goes to the participants of the study for their time in responding to the study questions.

Contributors YY contributed to the inception, survey design of the study, analysis, interpretation and manuscript writing. AA contributed to the inception, survey design of the study, analysis, interpretation and manuscript writing. YKL contributed 
to the inception, survey design of the study, analysis, interpretation and manuscript writing. SM contributed to analysis, interpretation and manuscript writing. MM contributed to analysis, interpretation and manuscript writing.

Funding The authors have not declared a specific grant for this research from any funding agency in the public, commercial or not-for-profit sectors.

Competing interests None declared.

Patient consent for publication Not required.

Ethics approval Ethical clearance and approval was obtained from the Institutional Review Board (IRB) of Jimma University (letter reference number IRB00097\20). Verbal informed consent was sought from every respondent after explaining the confidentiality of the collected data. Reasonable physical distancing was kept between the involved individuals during data collection. Data collectors were observed for 14 days after the completion of the survey. The data were collected in a private condition and kept confidential.

Provenance and peer review Not commissioned; externally peer reviewed.

Data availability statement Data are available on reasonable request. All data relevant to the study are included in the article or uploaded as supplementary information. All relevant data are included within the paper. The data would be guarded carefully by our research team for the only purpose of this scientific study. So, interested, qualified researchers can access the data by requesting the author, YY (yemenu2007@gmail.com).

Supplemental material This content has been supplied by the author(s). It has not been vetted by BMJ Publishing Group Limited (BMJ) and may not have been peer-reviewed. Any opinions or recommendations discussed are solely those of the author(s) and are not endorsed by BMJ. BMJ disclaims all liability and responsibility arising from any reliance placed on the content. Where the content includes any translated material, BMJ does not warrant the accuracy and reliability of the translations (including but not limited to local regulations, clinical guidelines, terminology, drug names and drug dosages), and is not responsible for any error and/or omissions arising from translation and adaptation or otherwise.

Open access This is an open access article distributed in accordance with the Creative Commons Attribution Non Commercial (CC BY-NC 4.0) license, which permits others to distribute, remix, adapt, build upon this work non-commercially, and license their derivative works on different terms, provided the original work is properly cited, appropriate credit is given, any changes made indicated, and the use is non-commercial. See: http://creativecommons.org/licenses/by-nc/4.0/.

\section{ORCID iDs}

Yimenu Yitayih http://orcid.org/0000-0002-0300-394X

Argaw Ambelu http://orcid.org/0000-0003-1898-4100

\section{REFERENCES}

1 Wang C, Horby PW, Hayden FG, et al. A novel coronavirus outbreak of global health concern. Lancet 2020;395:470-3.

2 Hawryluck L, Gold WL, Robinson S, et al. SARS control and psychological effects of quarantine, Toronto, Canada. Emerg Infect Dis 2004;10:1206-12.

3 WHO. Coronavirus disease (COVID-19) pandemic. WHO emergencies (online). Available: https://www.who.int/emergencies/ diseases/novel-coronavirus-2019/situation-reports

4 World Health Organization. Coronavirus disease 2019 (COVID-19): situation report.

5 Wilder-Smith A, Freedman DO. Isolation, quarantine, social distancing and community containment: pivotal role for old-style public health measures in the novel coronavirus (2019-nCoV) outbreak. J Travel Med 2020;27:taaa020.

6 Niu Y, Xu F. Deciphering the power of isolation in controlling COVID-19 outbreaks. Lancet Glob Health 2020;8:e452-3.

7 Barbisch D, Koenig KL, Shih F-Y. Is there a case for quarantine? Perspectives from SARS to Ebola. Disaster Med Public Health Prep 2015;9:547-53.

8 Miles SH. Kaci Hickox: public health and the politics of fear, 2014. Available: http://www.bioethics.net/2014/11/kaci- hickox $\neg$ public $\neg$ hea Ith $\neg$ and $\neg$ the-politics $\neg$ of $\neg$ fear/ [Accessed 1 Apr 2020].

9 Pellecchia U, Crestani R, Decroo T, et al. Social consequences of Ebola containment measures in Liberia. PLoS One 2015;10:e0143036.

10 Mihashi M, Otsubo Y, Yinjuan X, et al. Predictive factors of psychological disorder development during recovery following SARS outbreak. Health Psychol 2009;28:91-100.
11 Jeong H, Yim HW, Song Y-J, et al. Mental health status of people isolated due to middle East respiratory syndrome. Epidemiol Health 2016;38:e2016048.

12 Brooks SK, Webster RK, Smith LE, et al. The psychological impact of quarantine and how to reduce it: rapid review of the evidence. Lancet 2020;395:912-20.

13 Ramalingaswami V. Psychosocial effects of the 1994 plague outbreak in Surat, India. Mil Med 2001;166:29-30.

14 Griffin RJ, Dunwoody S, Zabala F. Public reliance on risk communication channels in the wake of a cryptosporidium outbreak. Risk Anal 1998;18:367-75.

15 Weiss D, Marmar CR. The impact of the event scale-revised. In: Wilson J, Keane TM, eds. Assessing psychological trauma and PTSD: a practitioner's handbook. New York: Guilford Press, 1997: 399-411.

16 Kidane S, Stokmans M. ICT-based psycho-social trauma relief in refugee camps in Ethiopia. Tilburg University, 2018: 1-19.

17 Creamer M, Bell R, Failla S. Psychometric properties of the Impact of Event Scale - Revised. Behav Res Ther 2003;41:1489-96.

18 Weiss DS. The impact of event scale: revised. In: Wilson JP, Tang CS, eds. Cross-cultural assessment of psychological trauma and PTSD. New York: Springer, 2007: 219-38.

19 Chen C-S, Wu H-Y, Yang P, et al. Psychological distress of nurses in Taiwan who worked during the outbreak of SARS. Psychiatr Serv 2005;56:76-9.

20 Bastien $\mathrm{CH}$, Vallières $\mathrm{A}$, Morin $\mathrm{CM}$. Validation of the insomnia severity index as an outcome measure for insomnia research. Sleep Med 2001;2:297-307

21 Chung K-F, Kan KK-K, Yeung W-F. Assessing insomnia in adolescents: comparison of insomnia severity index, Athens insomnia scale and sleep quality index. Sleep Med 2011;12:463-70.

22 Abiola T, Udofia O, Zakari M. Psychometric properties of the 3Item Oslo social support scale among clinical students of Bayero university Kano, Nigeria. MJP Online Early 2013;11.

23 Team RC. R: a language and environment for statistical computing, version 3.0. 2. Vienna, Austria: R Foundation for Statistical Computing, 2013.

24 Wang C, Pan R, Wan X, et al. Immediate psychological responses and associated factors during the initial stage of the 2019 coronavirus disease (COVID-19) epidemic among the general population in China. Int J Environ Res Public Health 2020;17:1729.

25 Qiu J, Shen B, Zhao M, et al. A nationwide survey of psychological distress among Chinese people in the COVID-19 epidemic: implications and policy recommendations. Gen Psychiatr 2020;33:e100213.

26 Livingston JD, Boyd JE. Correlates and consequences of internalized stigma for people living with mental illness: a systematic review and meta-analysis. Soc Sci Med 2010;71:2150-61.

27 Turan B, Budhwani H, Fazeli PL, et al. How does stigma affect people living with HIV? The mediating roles of internalized and anticipated HIV stigma in the effects of perceived community stigma on health and psychosocial outcomes. AIDS Behav 2017;21:283-91.

28 Earnshaw VA, Chaudoir SR. From conceptualizing to measuring HIV stigma: a review of HIV stigma mechanism measures. AIDS Behav 2009;13:1160.

29 Davtyan M, Brown B, Folayan MO. Addressing Ebola-related stigma: lessons learned from HIV/AIDS. Glob Health Action 2014;7:26058.

30 Davtyan M, Brown B, Folayan MO. Addressing Ebola-related stigma: lessons learned from HIV/AIDS. Glob Health Action 2014;7:26058.

31 Johnson DR, Lubin H, Rosenheck R, et al. The impact of the homecoming reception on the development of posttraumatic stress disorder. the west haven homecoming stress scale (WHHSS). $J$ Trauma Stress 1997;10:259-77.

32 Schaefer C, Coyne JC, Lazarus RS. The health-related functions of social support. J Behav Med 1981;4:381-406.

33 Cohen S, Wills TA. Stress, social support, and the buffering hypothesis. Psychol Bull 1985;98:310-57.

34 Vgontzas AN, Fernandez-Mendoza J, Liao D, et al. Insomnia with objective short sleep duration: the most biologically severe phenotype of the disorder. Sleep Med Rev 2013;17:241-54.

35 Baglioni C, Battagliese G, Feige B, et al. Insomnia as a predictor of depression: a meta-analytic evaluation of longitudinal epidemiological studies. J Affect Disord 2011;135:10-19.

36 Fernandez-Mendoza J, Calhoun SL, Bixler EO, et al. Sleep misperception and chronic insomnia in the general population: role of objective sleep duration and psychological profiles. Psychosom Med 2011;73:88-97.

37 Shechter A, Diaz F, Moise N, et al. Psychological distress, coping behaviors, and preferences for support among New York healthcare workers during the COVID-19 pandemic. Gen Hosp Psychiatry 2020;66:1-8. 